“(C) 2014 IEEE. Personal use of this material is permitted. Permission from IEEE must be obtained for all other uses, in any current or future media, including reprinting/republishing this material for advertising or promotional purposes, creating new collective works, for resale or redistribution to servers or lists, or reuse of any copyrighted component of this work in other works." 


\section{Systematic Reviews in Requirements Engineering: A Tertiary Study}

\author{
Muneera Bano, Didar Zowghi \\ Faculty of Engineering and IT \\ University of Technology, Sydney \\ Sydney, Australia \\ [Muneera.Bano, Didar.Zowghi]@uts.edu.au
}

\author{
Naveed Ikram \\ Ibn-e-Sina Empirical Software Engineering Lab \\ Riphah International University \\ Islamabad, Pakistan \\ naveed.ikram@riphah.edu.pk
}

\begin{abstract}
There has been an increasing interest in conducting Systematic Literature Reviews (SLR) among Requirements Engineering (RE) researchers in recent years. However, so far there have been no tertiary studies conducted to provide a comprehensive overview of these published SLR in RE. In this paper we present a tertiary study of SLR that focus solely on RE related topics by following the guidelines of Evidence Based Software Engineering. We have conducted both automated search of major online sources and manual search of the RE and SLR related conferences and journals. Our tertiary study has identified 53 distinct systematic reviews published from 2006 to 2014 and reported in 64 publications. We have assessed the resulting SLR for their quality, and coverage of specific $R E$ related topics thus identifying some gaps. We have observed that the quality of SLR in RE has been decreasing over the recent years. There is a strong need to replicate some of these SLR to increase the reliability of their results for future RE research.
\end{abstract}

Index Terms - Requirements Engineering, Mapping Study, Systematic Literature Review, Tertiary Study

\section{INTRODUCTION}

In early 1990's, RE emerged as a discipline of its own and dedicated conferences (e.g. ICRE, ISRE, REFSQ) and a journal (REJ) were established to promote the research in RE [1]. RE research community has made significant progress on various fronts and has accumulated a large body of knowledge to deliver new processes, tools, techniques, methods and frameworks [2]. Attempts have been made with traditional reviews (e.g. [1, 2]) as well as systematic reviews to aggregate and present the state of the art on various RE topics, e.g. Elicitation Techniques [3], Requirements change and Evolution [4, 5], and user related issues [6].

Systematic Literature Reviews are secondary studies that provide a way of synthesizing the available primary studies in empirical literature on a particular topic [7]. SLR is distinguished from a traditional review as it follows a rigorous and scrupulous procedure for search and selection of the sample studies in review. It is methodical and meticulous process of collecting and collating the acceptable quality published empirical studies based on a systemic protocol to reduce bias and provide transparency to the process. The process is formally documented and hence repeatable. There are three types of SLR [7, 8]:

Conventional SLR: they provide review of a focused and fine-grained research question(s) and would employ quantitative assessment on the results form primary studies.

Systematic Mapping Studies: that aim to find and classify the studies in a specific area and have a broader research question. They are helpful in identifying available primary studies before conducting SLR. They use the same search and selection procedure as conventional SLR but their focus is on the classification of the resulting studies to provide a map of the research in that area. Tertiary study: An SLR that aggregates the data and information from a number of existing SLR on a specific topic or area of research is called as Tertiary study [8].

A tertiary study aims to provide information about the available published SLR on a specific topic and tabulate the information regarding these SLR, e.g. the number of SLR published, their quality and the focus of those SLR within the topic of interest. Various tertiary studies have been published in software engineering recently e.g. [8-11], but to the best of our knowledge none of them focus on aggregating the SLR for RE.

In this paper we present for the first time a tertiary study that aims to identify all the SLR published about RE related topics by following EBSE guidelines [7]. Our objective is to present the topics covered by these SLR and the number of primary studies found in those SLR to create a richer picture of the empirical research in RE thus far. Our study has identified 53 distinct Systematic Reviews in RE related areas published from 2006 to 2014 and reported in 64 publications. Our tertiary study reported in this paper is also the first step in our larger research plan for contributing to an updated roadmap of RE following the roadmaps published in 2000 [1] and 2007 [2].

Section II gives details of the Systematic Review Planning and Execution. Section III presents the results of review process and discusses our answers to the research questions. Section IV describes limitations of the results, and section VI states the conclusion and suggests future works. 


\section{SYSTEMATIC MAPPING TERTIARY STUDY}

According to the EBSE guidelines there are three main phases of a Systematic Review [7], planning, execution and reporting results.

\section{A. Planning}

During the planning phase we developed a formal protocol containing the details of the strategies for search and selection process, quality assessment, data extraction, data synthesis and data analysis. Our tertiary study was guided by three research questions:

RQ1: What are the main areas of research in $R E$ that have been covered by published SLR?

$R Q 2:$ What is the quality of the published SLR in RE like?

$R Q 3:$ What are the gaps in the coverage of $R E$ research topics in the published SLR?

To answer RQ1, based on the publication titles and abstracts, we identified topics of SLR and grouped similar studies together under the same category. The reason for this exercise was not only to identify the coverage but also to identify gaps in the RE research (RQ3). The number of primary studies identified by these SLR shows the coverage of empirical work within their area of focus in RE.

To answer RQ2, we assessed both the quality of the SLR and the quality of the publications. We used the quality assessment checklist from previously published tertiary studies (e.g. $[8,9,11])$ for evaluating the SLR as a whole (grouping multiple publications together where applicable). These tertiary studies have utilized the criteria defined by the Centre for Reviews and Dissemination (CDR) Database of Abstracts of Reviews of Effects (DARE), of the York University. It includes four questions for assessing quality of an SLR as shown in Table I. The quality assessment criteria were applied on the whole study rather than on every single publication from that study due to the fact that all required information may not be found in a single publication especially if it is a conference or a workshop paper due to space limitation.

TABLE I. QA CRITERIA (ADAPTED FROM $[8,9,11]$ )

\begin{tabular}{|l|l|l|l|}
\hline QA Criteria & Answers & Scores & Description \\
\hline $\begin{array}{l}\text { QA1: Inclusion / } \\
\text { Exclusion }\end{array}$ & Yes & 1 & $\begin{array}{l}\text { Explicit inclusion / exclusion } \\
\text { criteria defined }\end{array}$ \\
\cline { 2 - 4 } & Partial & 0.5 & Implicit study selection \\
\cline { 2 - 4 } & No & 0 & No criteria defined \\
\hline $\begin{array}{l}\text { QA2: Search } \\
\text { Space Adequacy }\end{array}$ & Yes & 1 & $\begin{array}{l}\text { 4 or more digital libraries searched } \\
\text { as well as additional search } \\
\text { strategies applied }\end{array}$ \\
\cline { 2 - 4 } & Partial & 0.5 & $\begin{array}{l}\text { 3 or 4 digital libraries searched with } \\
\text { no extra search strategy }\end{array}$ \\
\cline { 2 - 4 } & No & 0 & $\begin{array}{l}\text { 2 or below digital libraries or very } \\
\text { restricted search }\end{array}$ \\
\hline $\begin{array}{l}\text { QA3: Quality } \\
\text { Assessment of } \\
\text { Primary Studies }\end{array}$ & Yes & 1 & $\begin{array}{l}\text { Explicit quality criteria described } \\
\text { and applied }\end{array}$ \\
\cline { 2 - 4 } & Partial & 0.5 & Implicit quality assessment \\
\cline { 2 - 4 } & No & 0 & $\begin{array}{l}\text { No quality assessment criteria } \\
\text { defined or used }\end{array}$ \\
\hline $\begin{array}{l}\text { QA4: } \\
\text { Information } \\
\text { regarding } \\
\text { Primary Studies }\end{array}$ & Yes & 1 & $\begin{array}{l}\text { Complete information presented } \\
\text { about primary studies }\end{array}$ \\
\cline { 2 - 4 } & Nortial & 0.5 & $\begin{array}{l}\text { Summary of information presented } \\
\text { about primary studies }\end{array}$ \\
\cline { 2 - 4 } & No & 0 & $\begin{array}{l}\text { The results of individual studies are } \\
\text { not specified }\end{array}$ \\
\hline
\end{tabular}

For assessing the individual publication quality, we used Google Scholar citation count as criteria. Citation count is considered as a measure of the impact of the publication on relevant research community. The citation count was checked on $19^{\text {th }}$ May 2014.

We had two major search terms in our study: "Requirements Engineering" AND "Systematic Literature Review". We conducted pilot testing on the major search terms to identify relevant terms and synonyms used in published literature for them. We also consulted previously conducted tertiary studies and systematic reviews on RE to complete our set of keywords for the search strings. Concatenating all the keywords with Boolean operators resulted in the following search string:

((requirements engineering $O R$ requirements process $O R$ requirements development $O R$ requirements elicitation $O R$ requirements gathering $O R$ requirements identification $O R$ requirements discovery $O R$ requirements analysis $O R$ requirements specification $O R$ requirements validation $O R$ requirements verification $O R$ requirements testing $O R$ requirements checking $O R$ requirements negotiation $O R$ requirements documentation $O R$ requirements management $O R$ requirements change management) AND (review of studies $O R$ structured review OR systematic review OR literature review OR systematic literature review $O R$ literature analysis $O R$ in-depth survey $O R$ literature survey $O R$ meta-analysis $O R$ analysis of research OR empirical body of knowledge OR overview of existing research OR body of published knowledge OR mapping OR mapping studies))

We applied the string on IEEE xplore, ACM DL, Science Direct, Google Scholar and EI Compendex. The string was customized for different online databases according to their interface requirements while keeping the logical order consistent. We did not apply any limit on the year of publication for our results. To triangulate our results we also performed snowball sampling technique and did manual searches of the references in four previously published tertiary studies (i.e. [8-11]). To further ensure the completeness of our review, we also checked the proceedings of the RE and SLR related conferences and journals from 2004 onwards (RE, EASE, ESEM, REFSQ, REJ, ESE and IST).

We filtered out the totally irrelevant studies by scanning the abstracts. The papers that reported normal literature reviews or surveys or bibliographic studies were also excluded from our list. We selected the studies only if they fulfilled all three of the following study selection criteria:

1. They were reported in English.

2. They were Systematic Review, Systematic Mapping Study or meta-analysis.

3. They were focusing on any area within Requirements Engineering.

As recommended in previous tertiary studies ([8-11]) we kept all multiple versions of publications from the same study and grouped them under same study ID as the conference and workshop papers have a page limit and may not be able to explain the whole SLR process in details. Based on the guidance provided in [12], we extracted 
publication details showing characteristics of the included SLR (i.e. title, authors, year of publication, type of publication, conference / journal name and complete reference, and number of citations to that paper) and information required to answer our three RQs (i.e. number of primary studies, focus of SLR). The grouping of main topics covered by the selected SLR (first column of Table VI), was done by applying thematic analysis [12] of the titles and abstracts of selected publications.

\section{B. Execution}

Appendix A shows the full reference list of the included publications. We assigned them IDs based on the study so that multiple publications from the same study are grouped under the same ID with suffix A, B and C. These studies are referred to by their IDs in the rest of this paper.

The search string was customized to be applied on all the selected digital libraries on the titles. The whole process for primary searches (as presented in Table II) resulted in 267 eligible studies out of which 91 passed the selection criteria described above. The secondary searches found 5 SLR that were not retrieved in the primary search process. S42 was found from [10], S45 from [11], S47 from [9], S34[B] was found from ESE and S44 was found from REJ. S42, S45 and S47 were not retrieved in our primary searches as we applied the search string on the titles of the papers to reduce the huge number of irrelevant results that was expected due to the string being too broad. The titles of these papers did not have required terms of our search string. S44 was found in REJ in November issue and S34[B] was in December issue of ESE. They were not found in the primary search results because the searches were conducted in October 2013. After secondary searches and inclusion/exclusion and discarding duplicates we were finally left with 53 unique SLR from 64 publications.

TABLE II. SEARCh EXECUTION AND STUdy SELECTION SUMmary

\begin{tabular}{|c|c|c|c|}
\hline \multicolumn{2}{|c|}{ Sources } & Papers Found & Included Papers \\
\hline \multirow{5}{*}{ 店 } & Google Scholar & 87 & 43 \\
\hline & IEEE xplore & 41 & 12 \\
\hline & ACM DL & 58 & 13 \\
\hline & Science Direct & 40 & 7 \\
\hline & EI Compendex & 37 & 16 \\
\hline \multicolumn{2}{|c|}{ TOTAL } & 267 & 91 \\
\hline \multicolumn{3}{|c|}{ AFTER DISCARDING DUPLICATES } & 58 \\
\hline \multicolumn{2}{|c|}{ Secondary Searches } & $\begin{array}{l}1 \text { new found from [10] } \\
1 \text { new found from [11] } \\
1 \text { new found from [9] } \\
0 \text { new found form [8] } \\
1 \text { new found from REJ } \\
1 \text { new found from ESE }\end{array}$ & 6 \\
\hline \multicolumn{3}{|c|}{ TOTAL PUBLICATIONS } & 64 \\
\hline \multicolumn{3}{|c|}{ TOTAL STUDIES } & 53 \\
\hline
\end{tabular}

Out of 64 papers, we were not able to retrieve full paper for two studies i.e. S3 and S8, both of them are theses found on Google Scholar but we were unable to find the full documents. We were able to get PDF file for S40 found from Google Scholar, but unable to find any information regarding the channel of publication. Eight studies have been reported in two publications each (S7, S23, S24, S26, $\mathrm{S} 27, \mathrm{~S} 30, \mathrm{~S} 34, \mathrm{~S} 35)$ and one study is reported in three publications (S5A, B, and C). One SLR (S2) has extended second version conducted later to update the results.

\section{RESULTS AND DISCUSSION}

According to the results of our tertiary study, 53 systematic reviews have been performed on various RE topics reported in 64 publications (including conference papers, journal papers, theses, and technical reports). The time period for the publications in our result is from 2006 till 2014 (Figure 1). There has been a sudden increase in the number of publications since 2009 onwards. In our 64 resultant publications, there are 31 conference papers, 16 journal papers, 4 workshop papers, 4 technical reports, and 8 theses. We were unable to determine the type for one publication (S40) as the full details were not available online. Out of 53 studies there are 12 Systematic Mapping Studies (S4, S6, S7, S9, S10, S12, S21, S34, S43, S44, S45, and S46), one Meta-Analysis (S42), and the rest are all Systematic Literature Reviews.

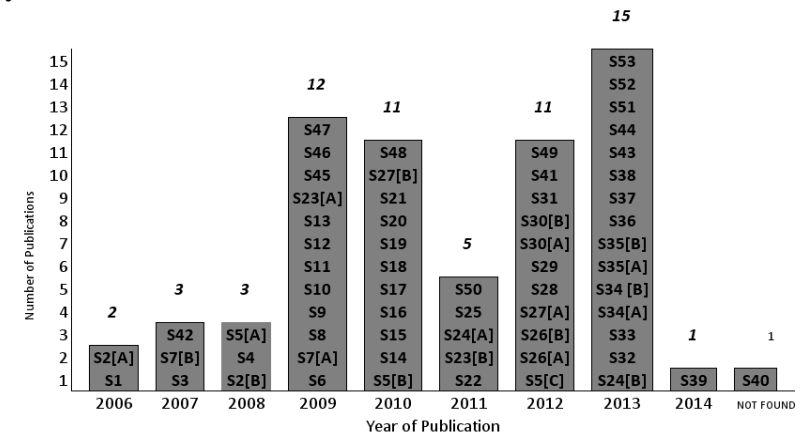

Fig. 1. Yearly distribution of the resulting SLR

TABLE III. TYPES OF PUBLICATION

\begin{tabular}{|l|l|l|}
\hline $\begin{array}{l}\text { CONFERENCE } \\
\text { PAPERS }\end{array}$ & $\begin{array}{l}\text { S2[A], S4, S5[A], S6, S10, S11, S14, S16, S18, S24[A], } \\
\text { S26[B], S27[A], S28, S29, S30[A], S31, S32, S33, } \\
\text { S35[B], S36, S37, S39, S42, S45, S46, S47, S48, S49, } \\
\text { S51, S52, S53 }\end{array}$ & 31 \\
\hline $\begin{array}{l}\text { JOURNAL } \\
\text { PAPERS }\end{array}$ & $\begin{array}{l}\text { S5[B], S5[C], S7[A], S9, S12, S15, S19, S20, S23[B], } \\
\text { S25, S34[A], S34[B], S38, S44, S50, S41 }\end{array}$ & 16 \\
\hline $\begin{array}{l}\text { WORKSHOP } \\
\text { PAPERS }\end{array}$ & S2[B], S22, S35[A], S43 & 4 \\
\hline $\begin{array}{l}\text { TECHNICAL } \\
\text { REPORTS }\end{array}$ & S23[A], S26[A], S27[B], S30[B] & 4 \\
\hline THESES & S1, S3, S7[B], S8, S13, S17, S21, S24[B] & 8 \\
\hline UNKNOWN & S40 & 1 \\
\hline
\end{tabular}

RQ1: What are the main research areas in $\mathrm{RE}$ that have been covered by the SLR?

Table IV shows the classification of the SLR according to their scope of study within RE for assessing the primary studies. 33 studies provided only state of the art within the area of RE that they focused whereas 7 SLR collected primary studies for assessing methods, 7 focused on Techniques, 4 on Tools and 1 each on Framework and Technology.

Table $\mathrm{V}$ presents the topics covered in RE by the resulting 53 studies and the coverage of primary studies by these SLR (column '\# of PS'). The number of primary studies in the SLR reported in RE range from highest 4089 (meta-analysis in S42) to lowest number 5 (S27). S42 provides meta-analysis of all publications of $\mathrm{RE}$ for the 
period of 1963-2006 regardless of being empirical or not. Four SLR have reported more than 200 primary studies in their area of focus within RE. S21 has reported 364 primary studies, S25 found 281, S24 found 242 and S4 found 240. According to Table VI these four SLR focus on the Value based Requirements Engineering (S21), User Requirements Notation (S25), state of the art in RE (S24), and Requirements Prioritization (S4). Five studies have found primary studies between 100 to $200(\mathrm{~S} 30 \rightarrow 100, \mathrm{~S} 20 \rightarrow$ $118, \mathrm{~S} 29 \rightarrow 125, \mathrm{~S} 7 \rightarrow 149, \mathrm{~S} 43 \rightarrow 177)$. There are four studies that found less than 10 primary studies in their area of focus $(\mathrm{S} 1 \rightarrow 8, \mathrm{~S} 13 \rightarrow 9, \mathrm{~S} 14 \rightarrow 8, \mathrm{~S} 27 \rightarrow 5)$. There are two possible explanations for the small number of primary studies that these four SLR have reported. Either these are neglected areas in empirical RE research or the SLR had limitations in locating all the relevant primary studies.

TABLE IV. CLASSIFICATION OF THE SCOPE OF THE RE SLR

\begin{tabular}{|c|c|c|}
\hline $\begin{array}{l}\text { State of the art on } \\
\text { the topic within } \\
\text { RE }\end{array}$ & $\begin{array}{l}\text { S1, S4, S6, S8, S9, S10, S11, S12, S15, S19, S20, } \\
\text { S21, S24, S25, S27, S28, S29, S30, S31, S33, } \\
\text { S34, S35, S37, S38, S41, S42, S43, S44, S45, } \\
\text { S48, S51, S52, S53 }\end{array}$ & 33 \\
\hline Methods & S3, S5, S7, S14, S18, S23, S32 & 7 \\
\hline Techniques & S2, S13, S16, S36, S46, S49, S50 & 7 \\
\hline Tools & S26, S39, S40, S47 & 4 \\
\hline Frameworks & S22 & 1 \\
\hline Technology & S17 & 1 \\
\hline
\end{tabular}

TABLE V. TOPICS AND NUMBER OF PRIMARY STUDIES COVERED IN RE SLR (NM=NOT MENTIONED, NF=NOT FOUND)

\begin{tabular}{|c|c|c|c|c|}
\hline $\begin{array}{l}\text { Grouping of main topics of } \\
\text { SLR }\end{array}$ & S-ID & Focus of SLR within the main topic & \# of PS & Year \\
\hline \multirow{6}{*}{ Non Functional Requirements } & S14 & Data Quality Requirements in a Software Product Development & 8 & 2010 \\
\hline & S15 & Security Requirements Engineering & 51 & 2010 \\
\hline & S17 & Decision support material to incorporate quality requirements technologies & 18 & 2010 \\
\hline & S18 & Quality Requirements Management & 46 & 2010 \\
\hline & S28 & Cloud Computing Security Requirements & 55 & 2012 \\
\hline & S33 & Cloud Computing Security Requirements and Solutions & 57 & 2013 \\
\hline \multirow{4}{*}{ Complete RE Process } & $\mathrm{S} 12$ & Technology transfer decision support in requirements engineering research & 97 & 2009 \\
\hline & S24 & Empirical Evidence in Requirements Engineering & 242 & 2013 \\
\hline & S42 & A quantitative assessment of requirements engineering publications-1963-2006 & 4089 & 2007 \\
\hline & S43 & 25 years of Requirements Engineering in Brazil & 177 & 2013 \\
\hline \multirow{3}{*}{ Model Driven Development } & S16 & Requirements Engineering techniques in model-driven development & 65 & 2010 \\
\hline & S23 & Transformation approaches between user requirements and analysis models & 29 & 2011 \\
\hline & $\mathrm{S} 40$ & Model-based Requirements Engineering Tool for Embedded Systems & 28 & $\mathrm{NF}$ \\
\hline \multirow{3}{*}{ Knowledge Management and RE } & $\mathrm{S} 26$ * & Wikis for Distributed Requirements Engineering & 29 & 2012 \\
\hline & S36 & Knowledge Creation in Requirements Engineering & 36 & 2013 \\
\hline & $\mathrm{S} 39 *$ & The Impact of Knowledge Sharing Platforms in Distributed Requirements Engineering Scenarios & 17 & 2014 \\
\hline \multirow{4}{*}{ RE in GSD } & S6 & Requirements Engineering in Distributed Software Development Environment & 12 & 2009 \\
\hline & S45 & Risks and safeguards for the requirements engineering process in global software development & 36 & 2009 \\
\hline & S51 & Situational factors affecting Requirement Engineering process in Global Software Development & NM & 2013 \\
\hline & \multicolumn{2}{|r|}{ * S26, S39: Overlapping with 'Knowledge Management and RE' } & & \\
\hline \multirow{2}{*}{ RE in Software Product Lines } & S19 & Requirements Engineering for Software Product Lines & 49 & 2010 \\
\hline & S20 & Requirements for Product derivation support & 118 & 2010 \\
\hline \multirow{2}{*}{ Requirements Management } & S22 & Goal Oriented Requirements Management frameworks for business process compliance & 88 & 2011 \\
\hline & S47 & Requirements Management Tools & 28 & 2009 \\
\hline Multi Agent Systems & S10 & Requirements engineering in the development of multi-agent systems & 58 & 2009 \\
\hline Requirements Reuse & S11 & Requirements Reuse & 18 & 2009 \\
\hline Value based RE & S21 & Value Based Requirements Engineering & 364 & 2010 \\
\hline Virtual Reality Systems & S37 & The Relationship between Requirements Engineering and Virtual Reality Systems & 12 & 2013 \\
\hline Web Engineering & S48 & RE in Web Engineering & 13 & 2010 \\
\hline Creativity in RE & S49 & Creativity Techniques for RE & 25 & 2012 \\
\hline \multirow{3}{*}{ Requirements Elicitation } & S2 & Requirements Elicitation Techniques & $26+13$ & 2008 \\
\hline & S38 & Automated Requirements Elicitation & 36 & 2013 \\
\hline & S50 & Requirements Elicitation Techniques & 30 & 2011 \\
\hline \multirow{3}{*}{ Stakeholders and users } & S5 & Stakeholder Identification Methods in Software Requirements & 45 & 2012 \\
\hline & S34 & User Involvement and System Success & 58 & 2013 \\
\hline & S35 & User Involvement in Requirements Engineering and System Success & 87 & 2013 \\
\hline \multirow{5}{*}{ Requirements Prioritization } & S1 & Software Requirements Prioritization & 8 & 2006 \\
\hline & S4 & Requirements prioritization based on benefit and cost prediction & 240 & 2008 \\
\hline & S13 & The effectiveness of requirements prioritization techniques for a medium to large number of requirements & 9 & 2009 \\
\hline & S31 & Software Requirements Triage and Selection & 23 & 2012 \\
\hline & S32 & Software Requirements Selection and Prioritization Using SBSE Approaches & 30 & 2013 \\
\hline Meta Modelling & S8 & Requirements Meta Models & 100 & 2009 \\
\hline \multirow{3}{*}{$\begin{array}{l}\text { Software Requirements } \\
\text { Specifications }\end{array}$} & S9 & Generation of requirements specifications from software engineering models & 24 & 2009 \\
\hline & S25 & User Requirements Notation & 281 & 2011 \\
\hline & S46 & Software Requirements Specifications Techniques & 46 & 2009 \\
\hline \multirow{2}{*}{$\begin{array}{l}\text { Requirements Verification / } \\
\text { Validation / Evaluation }\end{array}$} & S7 & Identification and classification of software requirement errors & 149 & 2009 \\
\hline & S30 & Requirement-based Software Testing With the UML & 100 & 2012 \\
\hline \multirow{2}{*}{ Requirements Traceability } & S3 & Requirements Tracing & $\mathrm{NF}$ & 2007 \\
\hline & S41 & Requirements Traceability & 52 & 2012 \\
\hline \multirow{2}{*}{$\begin{array}{l}\text { Requirements Change } \\
\text { Management }\end{array}$} & S27 & Causes of Requirements Change & 5 & 2012 \\
\hline & S29 & Requirements Evolution & 125 & 2012 \\
\hline RE Education & S44 & Requirements Engineering Education & 79 & 2013 \\
\hline Mobile Learning & S53 & A requirements catalog for mobile learning environments & 198 & 2013 \\
\hline Checklist for RE & S52 & Comprehensive Integrated Checklists for Requirements Engineering and Software Project Management & 323 & 2013 \\
\hline
\end{tabular}


RQ2: What is the quality of the published SLR in RE like?

We applied the Quality Assessment criteria described in Table I on all the studies. Figure 2 shows the distribution of the number of studies in different quality scores. Out of 53 we were able to retrieve 51 studies on which we could apply quality criteria (as we couldn't find full sources of S3 and S8). 42 studies out of 51 have scored 2 or above out of 4 . Figure 3 represents the number of studies classified according to the scores for each quality assessment question (see Table I).

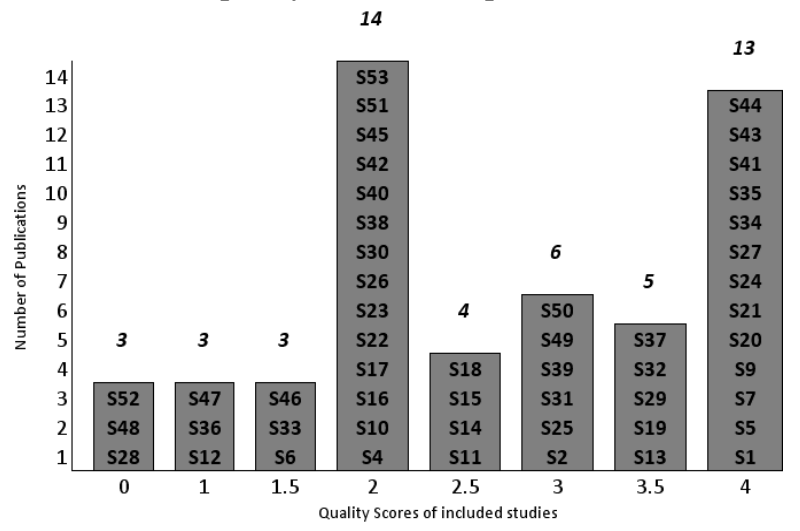

Fig. 2. Quality score distribution of the resulting SLR

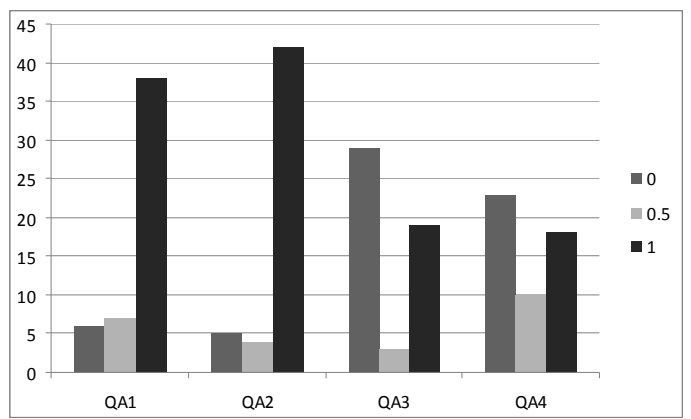

Fig. 3. Quality score distribution for each QA check from Table I

Table VI shows the most highly cited publications. For citations of all the studies see Appendix A. Regardless of the quality score, the highly cited papers are the ones published in prestigious conferences and journals related to RE and SLR community (i.e. RE, REJ, IST). S2[A] from Alan Davis et. al. published in 2006 has been cited 154 times showing a significant interest in the results of their SLR from RE research community. Figure 4 shows the average of the quality scores of the publication over the span of the years of their publication. Although in all years the quality of the SLR has average score of above 2, there is a decrease in quality score after 2009 with the increase in the number of SLR studies being published (Figure 2 and 4).

In previously published tertiary studies [8, 9], it was observed that the average quality scores of all the SLR in Software Engineering has increased over the years. According to Figure 1, for SLR in RE there is a sudden increase in the publications in 2009, but if we look at Figure 4, the average quality of the published SLR has decreased starting from the same year. One of the reasons in the decrease of the quality can be inferred from Figure 3. It shows that over half of the SLR have ignored to assess the quality of the included primary studies (QA3) and also neglected to provide an overview or summary of the included primary studies (QA4). The distinguishing factor of an SLR against a traditional literature review is the rigor of process but if the researchers would overlook this aspect then the results would not be as reliable and useful to the RE community. This is a serious issue worthy of further consideration because if the quality of the included primary studies is not assessed then there can be serious threats to the validity of the results produced by those SLR.

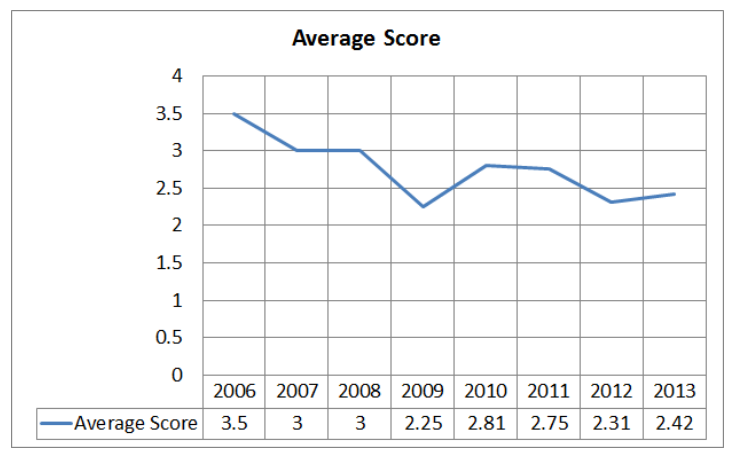

Fig. 4. Average of Quality Scores against the year of publication of SLR

TABLE VI. TOP 10 HIGHLY CITED SLR

\begin{tabular}{|l|l|l|l|}
\hline S-ID & GS Citations & Pub channel & QA Score \\
\hline S2[A] & 154 & RE & 3 \\
\hline S7[A] & 61 & IST & 4 \\
\hline S4 & 58 & RE & 2 \\
\hline S25 & 51 & JS & 3 \\
\hline S20 & 50 & IST & 4 \\
\hline S23[B] & 46 & REJ & 2 \\
\hline S50 & 43 & ITSE & 3 \\
\hline S15 & 42 & CSI & 2.5 \\
\hline S9 & 41 & IST & 4 \\
\hline S46 & 41 & ESEM & 1.5 \\
\hline
\end{tabular}

RQ3: What are the gaps in the coverage of $\mathrm{RE}$ research topics in the published SLR?

In answering this questions we were interested in three types of gaps in the SLR on RE. First, we considered the anomalies and potential conflicts in the reported number of primary studies in the SLR on the same topic by different authors in different years. Second, we were concerned about the small number of reported primary studies in some of the SLR. Finally, we observed some of the well known areas of RE research that seem to have been neglected by researchers who have conducted SLR.

1) Anomalies: In some cases, there are doubts about the number of primary studies included in the SLR as they are not providing a consistent view. For example, in Table V, for Requirements Prioritization, S1 has reported 8 primary studies from 1996 to 2005, whereas S4 has reported 240 primary studies from 1996 to 2007 . It is indeed very surprising to have found additional 232 published empirical studies on requirements prioritization in a span of just two years. When we look at the procedure followed by these two SLR (S1 and S4), although both of them were looking for empirical studies on requirements prioritization but they have searched with different search terms in their search strings, covered different 
number of data bases ( $\mathrm{S} 1$ has searched 8 sources whereas $\mathrm{S} 4$ has searched 14) and devised different inclusion/exclusion criteria. This raises concerns on the validity of SLR process adopted by $\mathrm{S} 1$ and also on the usefulness of the results for future RE researchers if they do not provide a complete and correct coverage within their area of focus.

Another example is the SLR on the state of the art in RE (S24) that has included 242 studies from the entire body of the empirical RE research literature. However, in Table V we see that S4 has 240, S21 has 364 and S25 has 281 primary studies on specific topics within RE. If a researcher is focusing on a specific topic within RE, then the number of included primary studies reported should have been a subset of the primary studies that were included in the state-of-the-art for the entire RE research literature (S24). The fact that this is not the case in these examples raises serious concerns both about the strict compliance to the EBSE guidelines as well as the reliable coverage of the published literature. There is a strong need for replicated studies on the similar topics to verify these results. If the protocol for the conduct of SLR is readily available, then replication of studies should be straightforward.

2) Lack of primary studies: The number of selected primary studies in table $\mathrm{V}$ is not uniform under all the related topics. Some topics report in excess of 300 primary studies whereas in others we observe less than 10 primary studies. For example, Data quality requirements (S14) and causes of requirements change $(\mathrm{S} 27)$ have the lowest number of primary studies selected. This could be due to two possible explanations: (a) the procedure followed by these SLR was not effective enough to find all the relevant primary studies, or (b) these are indeed neglected areas of empirical RE research and imply a need for further empirical exploration by the RE research community.

3) Ignored RE areas by SLR: We concede that the classification provided in Table $\mathrm{V}$ is neither exhaustive nor complete, as it does not represent all the areas of RE-related research covered in the literature. It only represents those RE research areas that our selected SLR has covered. For example, goal-oriented requirements engineering, requirements engineering in law, and requirements modeling notations have been the subject of many publications but not covered by any SLR so far. However, mapping the topics covered by the SLR against those suggested by [1, 2] for future research has enabled us to identify some of the current gaps in the RE research as described above. According to the RE roadmap by Chang and Atlee [2] published in 2007, further research within some 'hotspot' areas in RE have been suggested. Their roadmap was published around the time when RE researchers started showing interest in conducting systematic reviews. Among the identified topics by Chang and Atlee [2] for further research, the SLR in our results have addressed Security Requirements, RE education and curricula development, Requirements Reuse, Global and Distributed RE. The SLR have not covered the topics of Requirements Scaling, RE for self-management systems, effects of system environment on RE and effectiveness of $R E$ research in practice. Nuseibeh and Easterbrook [1] have highlighted two important areas within
RE: conflict resolution among requirements and requirements negotiation, which are not covered by any SLR so far.

\section{LIMITATIONS OF THE STUDY}

Though we have succeeded to closely follow the search strategy based on the guidelines of EBSE to ensure the completeness of our sample, but there is always a small risk that there would be some papers that were not included in our data collection due to their unavailability in electronic resources or because they may not have used the relevant keywords in their title or abstract. To mitigate this risk, we have attempted to triangulate our results with secondary searches. Out of the 64 included papers, we were unable to retrieve the publication details of one SLR (S40). We decided not to exclude this SLR in current results as we were interested to know any SLR conducted in all areas of RE that is available online. But for our future work for contributing to the development of a new roadmap of RE we will not be considering the non peer-reviewed studies or SLR with low quality score in our work.

To answer RQ1, we extracted the topics from the titles and abstracts of the selected SLRs. Then the first author grouped the extracted topics and appropriately named each group as listed in Table V. Although the other two authors then reviewed these names given to each group and agreed on the final names but it is possible that other researchers may select different titles for naming each group. In our future analysis of the RE SLRs, we plan to provide a short description for each group to provide further clarification of what is included in each group. For RQ2, as mentioned above, we have closely followed the quality assessment criteria recommended by the EBSE guidelines. Hence the quality of our quality assessment is as good as what those guidelines have provided. We anticipate that in future as the EBSE community evolves and matures, these guidelines may further be enhanced and improved thus increasing the confidence in the SLR quality assessment. We have also observed that the most cited SLR in RE, S2[A] from Davis et. al., does not show the highest quality score. Finally, for RQ3, we conceded that our gap analysis is neither complete nor exhaustive and it merely presents our preliminary observations. To make this a complete list requires deeper analysis of all selected primary studies.

\section{CONCLUSION AND FUTURE WORK}

The tertiary study reported in this paper has identified 53 unique SLR from 64 publications in the period 2006-2014. This paper represents the first ever tertiary study in the RE research literature. As such we anticipate that the data gathered and the results presented in this paper would be of great value to future RE researchers, in particular for doctoral students to provide an effective starting point for an overview of all the researched areas so far in RE. Furthermore, we have been able to identify various research gaps from our mapping that is beneficial for those interested in selecting fruitful areas of RE research. In this paper, we have also identified some of the anomalies in the results of already published SLR in RE that highlight potential opportunities for SLR replication in the 
future. Almost half of the selected SLR for our study have ignored to evaluate the quality of the primary studies included in their reviews. Careful attention should be paid to quality assessment criteria by future researchers.

This study is the first step in our research plan for contributing to an updated roadmap of $\mathrm{RE}$ following the roadmaps published in 2000 [5] and 2007 [4]. We are planning to retrieve all the citations from the published SLR and create a larger repository to combine the results within all the topics of $\mathrm{RE}$ in order to assess the strength of these areas for the future generations of RE researchers. Furthermore, we would like to contribute to the online RE bibliography created by Alan Davis [13] that is up to 2010 by updating the database to include publications from 2010 to 2014 [6].

\section{REFERENCES}

1. B. Nuseibeh and S. Easterbrook. Requirements engineering: a roadmap. in Proceedings of the Conference on the Future of Software Engineering. 2000: ACM.

2. B. H. Cheng, and J.M. Atlee. Research directions in requirements engineering. in Future of Software Engineering. 2007: IEEE Computer Society.

3. A. Davis, O. Dieste, A. Hickey, N. Juristo, and A. M. Moreno, 'Effectiveness of requirements elicitation techniques: Empirical results derived from a systematic review', in 14th IEEE International Conference Requirements Engineering, (RE 2006), pp. 179-188

4. M. Bano, S. Imtiaz, N. Ikram, M. Niazi, and M. Usman, 'Causes of requirement change-A systematic literature review', in 16th International Conference on Evaluation \& Assessment in Software Engineering (EASE 2012), pp. 22-31.

5. J. Li, H. Zhang, L. Zhu, R. Jeffery, Q. Wang, and M. Li, 'Preliminary results of a systematic review on requirements evolution', in 16th International Conference on Evaluation \& Assessment in Software Engineering (EASE 2012), pp. 12-21.

6. M. Bano, and D. Zowghi. User involvement in software development and system success: a systematic literature review. in Proceedings of the 17th International Conference on Evaluation and Assessment in Software Engineering. 2013: ACM.

7. B. Kitchenham and S. Charters, Guidelines for performing Systematic Literature Reviews in Software Engineering. 2007, EBSE Technical Report EBSE-2007-01.

8 B. Kitchenham, R. Pretorius, D. Budgen, O. Pearl Brereton, M. Turner, M. Niazi, and S. Linkman, 'Systematic literature reviews in software engineering-A tertiary study', Information and Software Technology, vol. 52, no. 8, pp. 792-805, 2010.

9. F. Q. B. da Silva, A. L. M. Santos, S. Soares, A. C. C. França, C. V. F. Monteiro, and F. F. Maciel, 'Six years of systematic literature reviews in software engineering: An updated tertiary study', Information and Software Technology, vol. 53, no. 9, pp. 899-913, Sep. 2011.

10. S. Imtiaz, M. Bano, N. Ikram, and M. Niazi, 'A tertiary study: experiences of conducting systematic literature reviews in software engineering', in Proceedings of the 17th International Conference on Evaluation and Assessment in Software Engineering, 2013, pp. 177-182.

11. J. M. Verner, et al. "Systematic literature reviews in global software development: A tertiary study." 16th International Conference on Evaluation \& Assessment in Software Engineering (EASE 2012), IET, 2012.
12. D. S. Cruzes and T. Dybå, 'Research synthesis in software engineering: A tertiary study', Information and Software Technology, vol. 53, no. 5, pp. 440-455, May 2011.

13. A. M. Davis, Requirements Bibliography. 1996-2010 [last accessed 19/05/2014]; Available from: http://www.reqbib.com/.

\section{APPENDIX A: Included Studies}

\begin{tabular}{|c|c|c|c|}
\hline \multicolumn{2}{|l|}{ ID } & Complete Reference & citation \\
\hline \multicolumn{2}{|l|}{$\mathrm{S} 1$} & $\begin{array}{l}\text { K. A. Khan, 'A systematic review of software requirements } \\
\text { prioritization', Masters Thesis Blekinge Inst. Technol. Ronneby } \\
\text { Swed., 2006. }\end{array}$ & 7 \\
\hline \multirow[t]{2}{*}{$\begin{array}{l}S \\
2\end{array}$} & A & $\begin{array}{l}\text { A. Davis, O. Dieste, A. Hickey, N. Juristo, and A. M. Moreno, } \\
\text { 'Effectiveness of requirements elicitation techniques: Empirical } \\
\text { results derived from a systematic review', in Requirements } \\
\text { Engineering, 14th IEEE International Conference, 2006, pp. 179- } \\
188 .\end{array}$ & 154 \\
\hline & B & $\begin{array}{l}\text { O. Dieste, M. Lopez, and F. Ramos, 'Updating a Systematic } \\
\text { Review about Selection of Software Requirements Elicitation } \\
\text { Techniques.' in } 11^{\text {th }} \text { WER, } 2008 \text {. }\end{array}$ & 14 \\
\hline \multicolumn{2}{|l|}{ S3 } & $\begin{array}{l}\text { C. Radl, “" A systematic literature review on requirements tracing } \\
\text { approaches”; Betreuer/in (nen): S. Biffl, M. Heindl; Institut für } \\
\text { Softwaretechnik und interaktive Systeme, 2007.' }\end{array}$ & 0 \\
\hline \multicolumn{2}{|l|}{ S4 } & $\begin{array}{l}\text { A. Herrmann and M. Daneva, 'Requirements prioritization based } \\
\text { on benefit and cost prediction: An agenda for future research', in } \\
\text { International Requirements Engineering, 2008. RE'08. 16th } \\
\text { IEEE, 2008, pp. 125-134. }\end{array}$ & 58 \\
\hline \multirow{3}{*}{$\begin{array}{l}S \\
5\end{array}$} & A & $\begin{array}{l}\text { C. Pacheco and I. Garcia, 'Stakeholder Identification Methods in } \\
\text { Software Requirements: Empirical Findings Derived from a } \\
\text { Systematic Review', in Software Engineering Advances, } 2008 \text {. } \\
\text { ICSEA'08. The Third International Conference on, 2008, pp. } \\
\text { 472-477. }\end{array}$ & 10 \\
\hline & B & $\begin{array}{l}\text { C. Pacheco and I. Garcia, 'Systematic Literature Review applying } \\
\text { to Stakeholder Identification Methods in Requirements } \\
\text { Engineering', IET Softw. August, } 2010 .\end{array}$ & 0 \\
\hline & $\mathrm{C}$ & $\begin{array}{l}\text { C. Pacheco and I. Garcia, 'A systematic literature review of } \\
\text { stakeholder identification methods in requirements elicitation', J. } \\
\text { Syst. Softw., vol. 85, no. 9, pp. 2171-2181, } 2012 \text {. }\end{array}$ & 8 \\
\hline \multicolumn{2}{|l|}{ S6 } & $\begin{array}{l}\text { T. Ebling, J. L. N. Audy, and R. Prikladnicki, 'A Systematic } \\
\text { Literature Review of Requirements Engineering in Distributed } \\
\text { Software Development Environments.', in ICEIS (3), 2009, pp. } \\
\text { 363-366. }\end{array}$ & 6 \\
\hline \multirow[b]{2}{*}{$\begin{array}{l}S \\
7\end{array}$} & A & $\begin{array}{l}\text { G. S. Walia and J. C. Carver, 'A systematic literature review to } \\
\text { identify and classify software requirement errors', Inf. Softw. } \\
\text { Technol., vol. 51, no. 7, pp. 1087-1109, } 2009 \text {. }\end{array}$ & 61 \\
\hline & B & $\begin{array}{l}\text { G. S. Walia and J. C. Carver, "Development of a requirement } \\
\text { error taxonomy as a quality improvement approach: A systematic } \\
\text { literature review," Department of Computer Science and } \\
\text { Engineering, Mississippi State University, MSU-070404, } 2007 .\end{array}$ & 0 \\
\hline \multicolumn{2}{|l|}{ S8 } & $\begin{array}{l}\text { F. Molina, J. Pardillo, C. Cachero, and A. Toval, 'A systematic } \\
\text { review of requirements metamodels', Technical report, } \\
\text { University of Murcia, 2008. Available online at http://www. } \\
\text { lucentia. es/index. php/MRM, 2009. }\end{array}$ & 1 \\
\hline \multicolumn{2}{|l|}{ S9 } & $\begin{array}{l}\text { J. Nicolás and A. Toval, 'On the generation of requirements } \\
\text { specifications from software engineering models: A systematic } \\
\text { literature review', Inf. Softw. Technol., vol. 51, no. 9, pp. 1291- } \\
1307,2009 \text {. }\end{array}$ & 41 \\
\hline \multicolumn{2}{|l|}{ S10 } & $\begin{array}{l}\text { D. Blanes, E. Insfran, and S. Abrahão, 'Requirements } \\
\text { engineering in the development of multi-agent systems: a } \\
\text { systematic review', in Intelligent Data Engineering and } \\
\text { Automated Learning-IDEAL 2009, Springer, 2009, pp. 510-517. }\end{array}$ & 6 \\
\hline \multicolumn{2}{|l|}{ S11 } & $\begin{array}{l}\text { F. B. de Azambuja, R. M. Bastos, and A. P. T. Bacelo, } \\
\text { 'Systematic Review of Requirements Reuse.', in SEKE, 2009, } \\
\text { pp. } 67-72 \text {. }\end{array}$ & 0 \\
\hline \multicolumn{2}{|l|}{$\mathrm{S} 12$} & $\begin{array}{l}\text { M. Ivarsson and T. Gorschek, 'Technology transfer decision } \\
\text { support in requirements engineering research: a systematic } \\
\text { review of REj', Requir. Eng., vol. } 14 \text {, no. 3, pp. 155-175, } 2009 \text {. }\end{array}$ & 32 \\
\hline \multicolumn{2}{|l|}{$\mathrm{S} 13$} & $\begin{array}{l}\text { Q. Ma, 'The effectiveness of requirements prioritization } \\
\text { techniques for a medium to large number of requirements: a } \\
\text { systematic literature review', AUT University, 2009. }\end{array}$ & 12 \\
\hline \multicolumn{2}{|l|}{ S14 } & $\begin{array}{l}\text { C. Guerra-García, I. Caballero, and M. Piattini, 'A Systematic } \\
\text { Literature Review of How to Introduce Data Quality , } \\
\text { Requirements into a Software Product Development.', in } \\
\text { ENASE, 2010, pp. 12-19. }\end{array}$ & 0 \\
\hline \multicolumn{2}{|l|}{ S15 } & $\begin{array}{l}\text { D. Mellado, C. Blanco, L. E. Sánchez, and E. Fernández-Medina, } \\
\text { 'A systematic review of security requirements engineering', } \\
\text { Comput. Stand. Interfaces, vol. 32, no. 4, pp. 153-165, } 2010 .\end{array}$ & 42 \\
\hline \multicolumn{2}{|l|}{ S16 } & $\begin{array}{l}\text { G. Loniewski, E. Insfran, and S. Abrahão, 'A systematic review } \\
\text { of the use of requirements engineering techniques in model- } \\
\text { driven development', in Model driven engineering languages and } \\
\text { systems, Springer2010, pp. 213-227. }\end{array}$ & 30 \\
\hline \multicolumn{2}{|l|}{ S17 } & $\begin{array}{l}\text { P. Saripalli, 'Decision support material to incorporate quality } \\
\text { requirements technologies: a systematic literature review and } \\
\text { industrial interviews', Norwegian University of Science and } \\
\text { Technology, 2010. }\end{array}$ & 0 \\
\hline
\end{tabular}




\begin{tabular}{|c|c|c|c|}
\hline \multicolumn{2}{|c|}{ S18 } & $\begin{array}{l}\text { R. B. Svensson, M. Host, and B. Regnell, 'Managing quality } \\
\text { requirements: A systematic review', in Software Engineering and } \\
\text { Advanced Applications (SEAA), } 2010 \text { 36th EUROMICRO } \\
\text { Conference on, 2010, pp. 261-268. }\end{array}$ & 15 \\
\hline \multicolumn{2}{|c|}{ S19 } & $\begin{array}{l}\text { V. Alves, N. Niu, C. Alves, and G. Valença, 'Requirements } \\
\text { engineering for software product lines: A systematic literature } \\
\text { review', Inf. Softw. Technol., vol. 52, no. 8, pp. } 806-820,2010 \text {. }\end{array}$ & 39 \\
\hline \multicolumn{2}{|c|}{ S20 } & $\begin{array}{l}\text { R. Rabiser, P. Grünbacher, and D. Dhungana, 'Requirements for } \\
\text { product derivation support: Results from a systematic literature } \\
\text { review and an expert survey', Inf. Softw. Technol., vol. 52, no. 3, } \\
\text { pp. 324-346, 2010. }\end{array}$ & 50 \\
\hline \multicolumn{2}{|c|}{ S21 } & $\begin{array}{l}\text { N. Jan and M. Ibrar, 'Systematic mapping of value-based } \\
\text { software engineering-a systematic review of value-based } \\
\text { requirements engineering', Technical report, Master Thesis no: } \\
\text { MSE-2010: 40, Karlskrona, Sweden, 2010. }\end{array}$ & 1 \\
\hline \multicolumn{2}{|l|}{$\mathrm{S} 22$} & $\begin{array}{l}\text { S. Ghanavati, D. Amyot, and L. Peyton, 'A systematic review of } \\
\text { goal-oriented requirements management frameworks for business } \\
\text { process compliance', in Requirements Engineering and Law } \\
\text { (RELAW), } 2011 \text { Fourth International Workshop on, 2011, pp. } \\
\text { 25-34. }\end{array}$ & 14 \\
\hline \multirow{2}{*}{$\begin{array}{l}S \\
2 \\
3\end{array}$} & A & $\begin{array}{l}\text { T. Yue, L. C. Briand, and Y. Labiche, 'A systematic review of } \\
\text { transformation approaches between user requirements and } \\
\text { analysis models' Carleton University, TR SCE-09-03, } 2009\end{array}$ & 0 \\
\hline & B & $\begin{array}{l}\text { T. Yue, L. C. Briand, and Y. Labiche, 'A systematic review of } \\
\text { transformation approaches between user requirements and } \\
\text { analysis models', REJ., vol. 16, no. 2, pp. } 75-99,2011 .\end{array}$ & 46 \\
\hline \multirow[t]{2}{*}{$\begin{array}{l}S \\
2 \\
4\end{array}$} & A & $\begin{array}{l}\text { T. Ambreen, M. Usman, N. Ikram, and M. Bano, 'Evidence in } \\
\text { Requirements Engineering: A Systematic Literature Review } \\
\text { Protocol', in ICSEA 2011, The Sixth International Conference on } \\
\text { Software Engineering Advances, 2011, pp. 576-580. }\end{array}$ & 0 \\
\hline & B & $\begin{array}{l}\text { T. Ambreen, ‘Evidence in Requirements Engineering: A } \\
\text { Systematic Literature Review’ IIUI } 2013\end{array}$ & 0 \\
\hline \multicolumn{2}{|l|}{ S25 } & $\begin{array}{l}\text { Amyot, Daniel, and Gunter Mussbacher. "User requirements } \\
\text { notation: The first ten years, the next ten years." Journal of } \\
\text { Software } 6.5 \text { (2011): 747-768. }\end{array}$ & 51 \\
\hline \multirow{2}{*}{$\begin{array}{l}S \\
2 \\
6\end{array}$} & A & $\begin{array}{l}\text { H. Lai, R. Peng, D. Sun, F. Shao, Y. Liu, and Y. Ni, 'A } \\
\text { systematic review of Re-specific wikis for distributed } \\
\text { requirements engineering', Wuhan Univ. Wuhan China Tech } \\
\text { Rep, vol. 2012530, 2012. }\end{array}$ & 1 \\
\hline & B & $\begin{array}{l}\text { Lai, Han, et al. "A Survey of RE-specific Wikis for Distributed } \\
\text { Requirements Engineering." Semantics, Knowledge and Grids } \\
\text { (SKG), } 2012 \text { Eighth International Conference on. IEEE, } 2012 .\end{array}$ & 1 \\
\hline \multirow{2}{*}{$\begin{array}{l}\text { S } \\
2 \\
7\end{array}$} & A & $\begin{array}{l}\text { M. Bano, S. Imtiaz, N. Ikram, M. Niazi, and M. Usman, 'Causes } \\
\text { of requirement change-A systematic literature review', in } \\
\text { Evaluation \& Assessment in Software Engineering (EASE 2012), } \\
\text { 16th International Conference on, 2012, pp. 22-31. }\end{array}$ & 1 \\
\hline & B & $\begin{array}{l}\text { Muneera Bano, Salma Imtiaz, Naveed Ikram, Muhammad } \\
\text { Usman, and Mahmood Niazi, "Systematic Literature Review for } \\
\text { Causes of Requirements Change", Technical Report: TR/2010- } \\
\text { 01, ISSN: 1353:7776, School of Computing and Mathematics, } \\
\text { Keele University, Keele, UK, } 2010\end{array}$ & 0 \\
\hline \multicolumn{2}{|l|}{ S28 } & $\begin{array}{l}\text { I. Iankoulova and M. Daneva, 'Cloud computing security } \\
\text { requirements: a systematic review', in Research Challenges in } \\
\text { Information Science (RCIS), } 2012 \text { Sixth International Conference } \\
\text { on, 2012, pp. 1-7. }\end{array}$ & 11 \\
\hline \multicolumn{2}{|c|}{ S29 } & $\begin{array}{l}\text { J. Li, H. Zhang, L. Zhu, R. Jeffery, Q. Wang, and M. Li, } \\
\text { 'Preliminary results of a systematic review on requirements } \\
\text { evolution', in Evaluation \& Assessment in Software Engineering } \\
\text { (EASE 2012), 16th International Conference on, 2012, pp. 12-21. }\end{array}$ & 3 \\
\hline \multirow{2}{*}{$\begin{array}{l}\mathrm{S} \\
3 \\
0\end{array}$} & A & $\begin{array}{l}\text { N. Asoudeh and Y. Labiche, 'Requirement-based Software } \\
\text { Testing With the UML: A Systematic Mapping Study', in ICSEA } \\
\text { 2012, The Seventh International Conference on Software } \\
\text { Engineering Advances, 2012, pp. 623-629. }\end{array}$ & 1 \\
\hline & B & $\begin{array}{l}\text { N. Asoudeh and Y. Labiche, "Requirement based software testing } \\
\text { in a UML context: A systematic literature review", Tech. Rep. } \\
\text { SCE-108,2011. Avialable from,squall.sce.carleton.ca/ pubs/ } \\
\text { tech_report /TR_SCE-11-08.pdf [retrieved: October, 2012] }\end{array}$ & 0 \\
\hline \multicolumn{2}{|l|}{ S31 } & $\begin{array}{l}\text { M. Khurum, N. Uppalapati, and R. C. Veeramachaneni, } \\
\text { 'Software Requirements Triage and Selection: State-of-the-Art } \\
\text { and State-of-Practice.', in APSEC, 2012, pp. 416-421. }\end{array}$ & 1 \\
\hline \multicolumn{2}{|c|}{ S32 } & $\begin{array}{l}\text { A. M. Pitangueira, R. S. P. Maciel, M. de Oliveira Barros, and A. } \\
\text { S. Andrade, 'A Systematic Review of Software Requirements } \\
\text { Selection and Prioritization Using SBSE Approaches', in Search } \\
\text { Based Software Engineering, Springer, 2013, pp. 188-208. }\end{array}$ & 1 \\
\hline \multicolumn{2}{|c|}{ S33 } & $\begin{array}{l}\text { P. Höner, 'Cloud Computing Security Requirements and } \\
\text { Solutions: a Systematic Literature Review',19th Twente Student } \\
\text { Conference on IT, June 24th, 2013, Enschede, The Netherlands. } \\
\text { Copyright 2013, University of Twente, Faculty of Electrical } \\
\text { Engineering, Mathematics and Computer Science. }\end{array}$ & 0 \\
\hline \multirow{2}{*}{$\begin{array}{l}\text { S } \\
3 \\
4\end{array}$} & A & $\begin{array}{l}\text { U. Abelein, H. Sharp, and B. Paech, 'Does Involving Users in } \\
\text { Software Development Really Influence System Success?', } \\
\text { Softw. IEEE, vol. 30, no. 6, pp. 17-23, } 2013 \text {. }\end{array}$ & 0 \\
\hline & B & $\begin{array}{l}\text { U. Abelein, B. Paech "Understanding the Influence of User } \\
\text { Participation and Involvement on System Success - a Systematic }\end{array}$ & 4 \\
\hline
\end{tabular}

\begin{tabular}{|c|c|c|c|}
\hline & & $\begin{array}{l}\text { Mapping Study" Empirical Software Engineering, pp 1-54, } \\
\text { December } 2013\end{array}$ & \\
\hline \multirow{2}{*}{$\begin{array}{l}S \\
3 \\
5\end{array}$} & A & $\begin{array}{l}\text { M. Bano and D. Zowghi, 'Users' involvement in requirements } \\
\text { engineering and system success', in Empirical Requirements } \\
\text { Engineering (EmpiRE), } 2013 \text { IEEE Third International Workshop } \\
\text { on, 2013, pp. 24-31. }\end{array}$ & 0 \\
\hline & B & $\begin{array}{l}\text { M. Bano and D. Zowghi, "User involvement in software } \\
\text { development and system success: a systematic literature review," } \\
\text { in Proceedings of the 17th International Conference on } \\
\text { Evaluation and Assessment in Software Engineering, 2013, pp. } \\
\text { 125-130. }\end{array}$ & 5 \\
\hline S36 & & $\begin{array}{l}\text { L. Schneider, K. Hajji, A. Schirbaum, and D. Basten, } \\
\text { 'Knowledge Creation in Requirements Engineering-A Systematic } \\
\text { Literature Review.', in Wirtschaftsinformatik, 2013, p. } 114 .\end{array}$ & 0 \\
\hline S37 & & $\begin{array}{l}\text { A. C. Santos, M. E. Delamaro, and F. L. Nunes, 'The } \\
\text { Relationship between Requirements Engineering and Virtual } \\
\text { Reality Systems: A Systematic Literature Review', in Virtual and } \\
\text { Augmented Reality (SVR), } 2013 \text { XV Symposium on, 2013, pp. } \\
\text { 53-62. }\end{array}$ & 0 \\
\hline S38 & & $\begin{array}{l}\text { H. Meth, M. Brhel, and A. Maedche, 'The State of the Art in } \\
\text { Automated Requirements Elicitation', Inf. Softw. Technol., } 2013 .\end{array}$ & 0 \\
\hline S39 & & $\begin{array}{l}\text { C. Sillaber and R. Breu, 'The Impact of Knowledge Sharing } \\
\text { Platforms in Distributed Requirements Engineering Scenarios: A } \\
\text { Systematic Review', in The 8th International Conference on } \\
\text { Knowledge Management in Organizations, 2014, pp. 579-591. }\end{array}$ & 0 \\
\hline $\mathrm{S} 40$ & & $\begin{array}{l}\text { S. Teufl, M. Khalil, and D. Mou, 'Requirements for a Model- } \\
\text { based Requirements Engineering Tool for Embedded Systems: } \\
\text { Systematic Literature Review and Survey'. }\end{array}$ & 0 \\
\hline S41 & & $\begin{array}{l}\text { Torkar, Richard, et al. "Requirements traceability: A systematic } \\
\text { review and industry case study." International Journal of } \\
\text { Software Engineering and Knowledge Engineering } 22.03 \text { (2012): } \\
385-433 \text {. }\end{array}$ & 9 \\
\hline S42 & & $\begin{array}{l}\text { A. Davis, et al., "A quantitative assessment of requirements } \\
\text { engineering publications-1963-2006," in Requirements } \\
\text { Engineering: Foundation for Software Quality, ed: Springer, } \\
\text { 2007, pp. 129-143. }\end{array}$ & 21 \\
\hline S43 & & $\begin{array}{l}\text { Oliveira, K., Pimentel,J., Santos,E., Dermeval,D., Guedes,G., } \\
\text { Souza,C., Soares, M., Castro,J., Alencar,F. and Silva, C. (2013) } \\
\text { " } 25 \text { years of Requirem ents Engineering in Brazil: a systematic } \\
\text { mapping". In: Proc. of the 16th Requirements Engineering } \\
\text { Workshop. Montevideo, Uruguay. Abr. }\end{array}$ & 1 \\
\hline S44 & & $\begin{array}{l}\text { Ouhbi, Sofia, Ali Idri, José Luis Fernández-Alemán, and } \\
\text { Ambrosio Toval. "Requirements engineering education: a } \\
\text { systematic mapping study." Requirements Engineering: p.1-20. } \\
\text { November } 2013\end{array}$ & 0 \\
\hline S45 & & $\begin{array}{l}\text { López, A., Nicolás, J., Toval, A., (2009) "Risks and safeguards } \\
\text { for the requirements engineering process in global software } \\
\text { development" Proceedings - } 2009 \text { 4th IEEE International } \\
\text { Conference on Global Software Engineering, ICGSE, pp. 394- } \\
399 \text {. }\end{array}$ & 20 \\
\hline S46 & & $\begin{array}{l}\text { Condori-Fernandez, N. et al. "A Systematic Mapping Study on } \\
\text { Empirical Evaluation of Software Requirements Specifications } \\
\text { Techniques", ESEM, 502-505, IEEE, } 2009 .\end{array}$ & 41 \\
\hline S47 & & $\begin{array}{l}\text { Rainera, Austen, Sarah Beechamb, and Cei Sandersona. "An } \\
\text { assessment of published evaluations of requirements management } \\
\text { tools." Proceedings of the 13th international conference on } \\
\text { Evaluation and Assessment in Software Engineering. British } \\
\text { Computer Society, 2009. }\end{array}$ & 4 \\
\hline S48 & & $\begin{array}{l}\text { Aguilar, José Alfonso, Irene Garrigós, Jose-Norberto Mazón, and } \\
\text { Juan Trujillo. "Web Engineering Approaches for Requirement } \\
\text { Analysis-A Systematic Literature Review." In WEBIST (1), pp. } \\
\text { 187-190. 2010. }\end{array}$ & 20 \\
\hline S49 & & $\begin{array}{l}\text { S. K. Saha, M. Selvi, G. Buyukcan, and M. Mohymen, 'A } \\
\text { systematic review on creativity techniques for requirements } \\
\text { engineering', in International Conference on Informatics, } \\
\text { Electronics \& Vision (ICIEV 2012), pp. 34-39. }\end{array}$ & 1 \\
\hline S50 & & $\begin{array}{l}\text { Dieste, Oscar, and Natalia Juristo. "Systematic review and } \\
\text { aggregation of empirical studies on elicitation techniques." IEEE } \\
\text { Transactions on Software Engineering } 37.2 \text { (2011): 283-304. }\end{array}$ & 43 \\
\hline S51 & & $\begin{array}{l}\text { Khan, H.H.; Bin Mahrin, M.N.; Bt Chuprat, S., "Situational } \\
\text { factors affecting Requirement Engineering process in Global } \\
\text { Software Development," Open Systems (ICOS), } 2013 \text { IEEE } \\
\text { Conference on, vol., no., pp.118,122, 2-4 Dec. } 2013\end{array}$ & 0 \\
\hline S52 & & $\begin{array}{l}\text { Suleiman, H.; Adepetu, A.; Arnautovic, E.; Svetinovic, D., } \\
\text { "Comprehensive Integrated Checklists for Requirements } \\
\text { Engineering and Software Project Management," Information } \\
\text { Science and Applications (ICISA), } 2013 \text { International Conference } \\
\text { on , vol., no., pp.1,4, 24-26 June 2013 }\end{array}$ & 0 \\
\hline S53 & & $\begin{array}{l}\text { Nemésio Freitas Duarte Filho and Ellen Francine Barbosa. } 2013 . \\
\text { A requirements catalog for mobile learning environments. } \\
\text { In Proceedings of the 28th Annual ACM Symposium on Applied } \\
\text { Computing (SAC '13). ACM, New York, NY, USA, 1266-1271. }\end{array}$ & 1 \\
\hline
\end{tabular}

